\title{
Migrações e Deslocamentos Humanos: reflexão à luz do contexto sul brasileiro
}

\author{
Migración y movimiento: La reflexión a La luz Del contexto brasileiro Del \\ Sur
Migration and Human Displacement: a reflection on the Brazilian South context

\author{
Saionara Tais Scalon ${ }^{1}$ \\ Ismael Pereira da Silva ${ }^{2}$ \\ Thais Janaina Wenczenovicz ${ }^{3}$
}

\begin{abstract}
Resumo
O presente estudo tem por objetivo refletir sobre os deslocamentos humanos ocorridos no início do século XXI ao Sul do Brasil tendo por motivação os desastres ambientais, especialmente os haitianos. Os homens imigram e migram de longa data, motivados por questões endógenas e exógenas. Muitos são os países da América Latina que vem recebendo essa categoria de (i)migrações impulsionadas pelo desemprego, fome, enfermidades, num conjunto que resulta em vulnerabilidade completa do ser humano. Enquanto procedimento metodológico utilizase do método bibliográfico-investigativo, associado ao uso de história oral temática (entrevistas).
\end{abstract}

Palavras-Chave: Migrações, Haitianos, Refugiados Ambientais, Sul do Brasil

\section{Resumen}

Este estudio tiene por objetivo reflexionar acerca de los desplazamientos humanos que se produjeron al principios del siglo XXI en el sur de Brasil, habiendo motivado por los desastres socio-ambientale, especialmente los haitianos. Hombres salen y migran desde hace mucho tiempo motivado por cuestiones endógenas y exógenas. Hay muchos países de la América Latina que ha recibido (i)migración por lo general impulsada por el desempleo, la hambre, la enfermedad, lo que resulta en un conjunto completo de vulnerabilizacion humana. Sin embargo, el procedimiento metodológico se utiliza los métodos bibliográficosinvestigación asociados con el uso de la historia oral (entrevistas).

Palabras claves: Migracione, Haitianos, Refugiados Ambientales, Sur de Brazil

\section{Abstract}

The present study aims to reflect on the human deslocations occurred at the beginning of the $21^{\text {st }}$ century in the South of Brazil, motivated by environmental disasters, especially haitians Men immigrate and migrate for a long time motivated by endogenous and exogenous issues. Many Latin American countries have been receiving this category of i)migrations generally driven by unemployment hunger, disease, resulting in complete vulnerability

\footnotetext{
${ }^{1}$ Bolsista Voluntária CNPq - Projeto Invisíveis e Vulneráveis: imigração haitiana no Sul do Brasil. Universidade Estadual do Rio Grande do Sul/UERGS.

${ }^{2}$ Bolsista CNPq - Projeto Invisíveis e Vulneráveis: imigração haitiana no Sul do Brasil. Universidade Estadual do Rio Grande do Sul/UERGS.

${ }^{3}$ Docente Adjunta e Pesquisador Sênior/Universidade Estadual do Rio Grande do Sul-UERGS.
} 
of the human being. As a methodolical procedure e use the bibliographic-investigative method, associated with the use of oral history (interviews).

Keywords: Migrations, Haitians, Environmental refugees, South of Brazil.

\section{Introdução}

Desde os primórdios da Humanidade o homem tem migrado por razões diversas, impulsionado por motivos endógenos e exógenos. Migra-se por questões culturais, econômicas, políticas e sociorreligiosas ou desastres ambientais e climáticos a exemplo do grupo em estudo. A imigração haitiana ao Brasil é um fenômeno migratório que ganhou grande proporção após o terremoto que abalou o país caribenho em 12 de janeiro de 2010 e provocou a morte de mais de milhares de pessoas e deixou outras tantas na condição de refugiados.

O Brasil é signatário dos principais tratados internacionais de direitos humanos e é parte da Convenção das Nações Unidas de 1951 sobre o Estatuto dos Refugiados e do seu Protocolo de 1967. O país promulgou, em julho de 1997, a sua lei de refúgio ( $\mathrm{n}^{\circ}$ 9.474/97), contemplando os principais instrumentos regionais e internacionais sobre o tema. A lei adota a definição ampliada de refugiado estabelecida na Declaração de Cartagena de 1984, que considera a "violação generalizada de direitos humanos" como uma das causas de reconhecimento da condição de refugiado. Em maio de 2002, o país ratificou a Convenção das Nações Unidas de 1954 sobre o Estatuto dos Apátridas e, em outubro de 2007, iniciou seu processo de adesão à Convenção da ONU de 1961 para Redução dos Casos de Apatridia. A lei brasileira de refúgio criou o Comitê Nacional para os Refugiados (CONARE), que atua principalmente com a formulação de políticas para refugiados no país, com a elegibilidade e também com a integração local de refugiados. Esta também garante documentos básicos aos refugiados, incluindo documento de identificação e de trabalho, além da liberdade de movimento no território nacional e de outros direitos civis. O número total de solicitações de refúgio aumentou mais de $2.868 \%$ entre 2010 e 2015 (de 966 solicitações em 2010 para 28.670 em 2015). A maioria dos solicitantes de refúgio vem da África, Ásia (inclusive Oriente Médio) e o Caribe, segundo a Agência da ONU para Refugiados.

Nos últimos dois anos, 15 mil imigrantes chegaram ao Estado do Rio Grande do Sul. Muitos deles fugiram de guerras e conflitos em seus países. Todos buscavam uma vida melhor no Brasil. O devido estudo trata da integração dos Imigrantes Haitianos junto à sociedade brasileira - mais especificamente na região norte do Rio Grande do Sul (Brasil) - 
tendo em vista sua relação junto às dimensões materiais e concepções das diretrizes inclusivas educacionais.

Nesse sentido, pretende-se demonstrar os fatores que impulsionaram o deslocamento desses imigrantes e o processo de alocação no Brasil, bem como em que medida as políticas de imigração ameaçam a manutenção dos Direitos Humanos de indivíduos provenientes de países com histórico de dependência e intransigência aos Direitos Fundamentais Civis e Sociais em seu país de origem. Tal condição corrobora na análise entre as políticas de integração e negação aos Direitos Humanos. Ao longo dos últimos vinte anos, o Brasil adotou uma série de novas políticas voltadas à gestão dos movimentos transfronteiriços e aos imigrantes no Brasil, políticas estas que respondem não somente ao ativismo dos migrantes e seus aliados, mas também à estratégia da política externa brasileira. Como procedimento metodológico, o devido trabalho utiliza-se da pesquisa bibliográfica ${ }^{4}$ acompanhado de análise de entrevistas (História Oral Temática). Foram utilizadas para elaboração desse estudo um total de 10 entrevistas.

\section{Sobre os deslocados/refugiados ambientais}

Está em evidência nos últimos anos em diversas áreas do conhecimento o uso dos termos 'deslocado', 'refugiado' e '(i)migrante'. Para tanto, sinalizamos que o termo deslocado em consonância a ACNUR indica:

[...] refugiados são pessoas que escaparam de conflitos armados ou perseguições. Com frequência, sua situação é tão perigosa e intolerável que devem cruzar fronteiras internacionais para buscar segurança nos países mais próximos, e então se tornarem um 'refugiado' reconhecido internacionalmente, com o acesso à assistência dos Estados, do ACNUR e de outras organizações. São reconhecidos como tal, precisamente porque é muito perigoso para eles voltar ao seu país e necessitam de um asilo em algum outro lugar. Para estas pessoas, a negação de um asilo pode ter consequências vitais. (ACNUR, 2017)

O termo refugiados ${ }^{5}$ vem ganhando destaque no cenário internacional a partir do século XX decorrente do conjunto de acontecimentos advindos da Primeira e da Segunda

\footnotetext{
${ }^{4}$ Serviram de leituras pontuais e iniciais os artigos de ESPIUCA, R.; WENCZENOVICZ, T.J. . Haitianos no Sul do Brasil: reflexões à luz do mundo do trabalho. In: Cristhian Magnus De Marco; Magda Cristiane Detsch da Silva; Orides Mezzaroba. (Org.). Diálogos sobre Direito e Justiça. 1ed.Joaçaba/SC: Editora Unoesc, 2017, v. 2, p. 405-424. WENCZENOVICZ, THAÍS JANAINA; ESPIUCA, R. . Migrant workers in the northen part of Rio Grande do Sul (Brazil): integration end (dis) respect of the Rigths related to personality. Revue Européenne du Droit Social, v. XXXIII, p. 60-76, 2016.

${ }^{5}$ Para esse artigo utiliza-se o termo em consonância ao conceituado pela ACNUR (Agência da ONU para Refugiados).
} 
Guerra Mundial, em decorrência do contexto histórico. Esses geraram os maiores deslocamentos humanos já vistos na História do mundo moderno e contemporâneo, resultado da maior violência social já feita. Para garantir a proteção foram criados diversos órgãos multilaterais de proteção e um eixo legal humanitário para esses refugiados em nível mundial. (COSTA, 2009).

Em 1943 foi estabelecida a administração das Nações Unidas para o Auxilio e Restabelecimento (ANUAR) a qual prestava auxilio aos refugiados e pessoas que por motivo bélico estivessem em situação de deslocados. Com o fim da Segunda Guerra Mundial a ANUAR inicia o processo de retorno desses refugiados para seu país de origem, que apesar das recusas pelo retorno, foram forçados a retornar para seu país de origem.

A ANUAR logo foi substituída pela Organização Internacional para os Refugiados (OIR), sendo o primeiro organismo internacional a tratar dos aspectos relacionados aos refugiados, prestando assistência e proteção política e jurídica. Mais tarde, em 1949 em Assembleia Geral da ONU foi estabelecido o Acnur - Alto Comissariado das Nações Unidas para os Refugiados, uma organização humanitária e social de grande importância na Proteção aos Direitos Humanos, chegando amparar aproximadamente 50 milhões de pessoas. Logo, em 1951 a ONU elabora o primeiro instrumento internacional de proteção aos refugiados. Tratase da Convenção Relativa ao Estatuto do Refugiado, que vigorou em 21 de abril de 1954, onde ambas estavam empenhadas pela busca por soluções para esses grupos.

Sabe-se que o direito internacional define e protege os refugiados através da Convenção da ONU de 1951 sobre o Estatuto dos Refugiados e seu protocolo de 1967, assim como a Convenção da OUA (Organização da Unidade Africana) - pela qual se regularam os aspectos específicos dos problemas dos refugiados na África em 1969 - ou a Declaração de Cartagena de 1984 sobre os Refugiados continuam sendo a chave da atual proteção dos refugiados.

O Brasil foi um dos pioneiros a regulamentar a proteção aos refugiados. E no âmbito internacional o primeiro a aprovar a Convenção de 1951, já em 1960, bem como elaborar uma Lei especifica sobre os Refugiados.

A Lei 9.474, de 22 de julho de 1997, instituiu o Comitê Nacional de Refugiados e tem como finalidade analisar as solicitações de refugio, definir os direitos e deveres dos refugiados e ainda de prestar assistência aos mesmos, com mecanismos para implantação do Estatuto dos Refugiados através da Lei 6.815/80 onde define sendo o individuo aquele que devido a fundados temores de perseguição por motivos de raça, religião, nacionalidade, grupo social ou opiniões políticas encontra-se fora de seu país de nacionalidade e não possa ou não 
queira acolher-se à proteção de tal país; não possuindo nacionalidade e estando fora do país onde antes possuía sua residência, não possa ou não queira regressasse a ele, em função das perseguições descritas no inciso anterior e ainda devido à grave e generalizada violação de direitos humanos, é obrigado a deixar seu país de nacionalidade para buscar refúgio em outro país (ESTATUTO DO ESTRANGEIRO, 1980).

Associado ao Estatuto do Estrangeiro surgia à política de controle, onde o imigrante era visto como uma ameaça à segurança nacional, ${ }^{6}$ entretanto aqueles que tinham mão de obra qualificada eram privilegiados uma vez que o país necessitava de mão-de-obra. Assim o Brasil transitava por um processo de restauração democrática e do estado de direito pósditadura que inicia um reconhecimento como um país preocupado com questões ligadas ao estrangeiro.

O Estatuto determina a condição jurídica do imigrante e instituiu o Conselho Nacional de Imigração (CNIg), órgão colegiado e vinculado ao Ministério do Trabalho e emprego. Ainda decide sobre a entrada do estrangeiro em território brasileiro e o tipo de visto para sua admissão.

Já os refugiados ambientais são identificados como grupo humano que migra por força dos acontecimentos do ambiente natural e da natureza. ${ }^{7}$ A Organização Internacional das Migrações (OIM) adota a seguinte definição de refugiados ambientais:

[...] pessoas ou grupo de pessoas que, devido a alterações repentinas ou progressivas no meio ambiente, foram adversamente afetadas em suas vidas e, devido às condições que se encontram, decidem ou são obrigadas a deixar as suas casas" (ACNUR, 2011)

Nesse interim de não definição de categoria/conceito, os refugiados ambientais ficam vulneráveis a interpretação de organismos oficiais em muitos momentos. Associa-se a essa condição a dificuldade na comunicação (matriz linguística), liberação de documentos de ingresso e permanência, acesos aos direitos fundamentais, alojamento, dentre outros. Segundo o Relatório de 2016 do Comitê Nacional para os Refugiados, órgão ligado ao Ministério da Justiça ocorreu um crescimento de $2.868 \%$ de refugiados entre 2010 e 2015, onde haitiano,

\footnotetext{
${ }^{6}$ Para esse tema recomenda-se a leitura do artigo de Antônio Tadeu Ribeiro de Oliveira intitulado Os invasores: as ameaças que representam as migrações subsaariana na Espanha e haitiana no Brasil. Disponível em: http://www.scielo.br/pdf/remhu/v23n44/1980-8585-REMHU-23-44-135.pdf

${ }^{7}$ Cabe aqui ressaltar que existe uma corrente doutrinária que defende a inexistência do refúgio como modalidade do asilo. Para os pesquisadores recomenda-se utilizar o termo asilo e, portanto, os solicitantes de refúgio seriam, na verdade, homens e mulheres que buscam asilo. Tal corrente predomina no hemisfério norte, mas na América Latina entende-se que existem dois institutos assemelhados, porém diferentes: o refúgio e o asilo. Ver em: Jubilut LL. O procedimento de Concessão de Refúgio no Brasil. 2007 [acesso 20 junho 2017]. Disponível em: www.mj.gov.br/services/.../FileDownload.EZTSvc.asp
} 
senegaleses, sírios, bengaleses e nigerianos pertencem ao grupo das cinco nacionalidades que mais solicitam. (ACNUR, 2016)

Apesar desses refugiados não serem vitimas de perseguições, são obrigados a deixar o território de origem ou residência pelo fato de não haver mais possibilidades de sobreviver nesses locais. São refugiados a procura de abrigo, e costumeiramente sem expectativa de retorno para os locais de origem a curto prazo. No Brasil a Lei do imigrante busca que eles tenham o mesmo direito que o cidadão brasileiro tenha como carteira de trabalho além de muitos outros que são negados, devido ao preconceito, xenofobia e abuso do poder. Além da falta de oportunidades e o acesso a diferentes espaços na sociedade (SILVA e WENCZENOVICZ, 2017).

É importante reconhecer e categorizar essas pessoas, pois eles se encontram em situação de vulnerabilidade socioambiental, e essa condição de minimização social sinaliza a cada dia mais a necessidade de garantir direitos e dignidade humana a todos. Além de obrigação dos Estados - que devem garantir direitos mínimos aceitos e assumidos através das Declarações, Pactos Internacionais e demais urge nesse contexto os direitos humanitários.

\section{Haitianos: reflexões pontuais em perspectivas brasileiras}

A história do país de origem desses imigrantes - O Haiti - continua ligado a uma rede de dependências múltiplas e a um conjunto de relações de dominação que têm como força motriz o capitalismo em escala mundial. As possibilidades de desenvolvimento no Haiti e sua vida nacional são amplamente condicionadas pela natureza das relações que estabelece no chamado sistema internacional, mas também pela evolução desse sistema, ou seja, das correlações de força que ali se instalaram, se arraigam e se transformam.

Em virtude dessa saga humana que consolida o drama haitiano e sua conversão a país mais pobre da América. O preço a ser pago pela Independência é cobrado ainda pelas potências ultraliberais, e o fardo dele repercute de forma decisiva nas condições de vida do povo haitiano. E buscar melhores condições de vida ou sobrevivência torna-se uma ação comum há a diversos anos os deslocamentos humanos.

Com o terremoto que atingiu o Haiti, em 12 de Janeiro de 2010, e que causou a morte demais de 200.000 pessoas, deixando mais de 1.500 .000 sem abrigo e inaugurando um novo ciclo trágico de contágio e morte por cólera, as condições de vida no país, que já eram precárias, se deterioraram ainda mais. Hospitais, escolas, prédios públicos e universidades 
foram destruídos, e isto se torna ainda mais trágico se levarmos em conta que tais estruturas já eram muito limitadas e incapazes de absorver os haitianos antes mesmo do abalo sísmico.

A existência humana no Haiti torna-se cada vez mais difícil, de modo que os fatores de expulsão intensificaram sua atuação sobre a dinâmica migratória no país. Costumeiramente, a viagem é feita de carona, avião, trem, ônibus e até em caçamba de caminhão. A bagagem feita com ordem e sentimento vai se desfazendo a cada nova fronteira a qual se deparam ou órgão fiscalizador. Aos que viajam por meio dos agenciadores e coiotes a viagem transforma-se em experiência exaustiva e perigosa. ${ }^{8}$

O Acre figura dentre os Estados que primeiramente receberam os imigrantes haitianos no Brasil. Segundo dados da Polícia Federal (2014), aportaram no Acre - desde dezembro de 2010, cerca de 130 mil haitianos utilizando-se da fronteira do Peru com o Estado e se instalaram de forma precária ainda nos estados do Amazonas, Mato Grosso, Mato Grosso do Sul e do Pará. Calcula-se que entre janeiro e setembro do ano de 2011, foram 6 mil e, em 2012, foram 2.318 haitianos que entraram ilegalmente no Brasil. Posterior o fluxo migratória também inseriu os Estados do Sudeste e Sul do Brasil - Paraná, Santa Catarina e Rio Grande do Sul.

Para a regularização dos haitianos no Brasil entrou em vigor a Resolução no 97/2012 do Conselho Nacional do Imigrante para conceder vistos mensais, para que esses grupos possam sair da situação de vulnerabilidade que se encontram no momento que resolvem migrar para o Brasil, aonde muitos chegam por rotas ilegais, vitimas de ações de atravessadores ou quadrilhas de trafico internacional de pessoas. Na mesma resolução em seu artigo $2^{\circ}$ considera a razão humanitária devido ao agravamento das condições de vida da população haitiana decorrente do terremoto de 2010.

De acordo com a Resolução o visto terá caráter especial concedido pelo Ministério das Relações Exteriores, com validade de cinco anos, podendo ser renovado de acordo com as condições trabalhistas que se encontram no Brasil. Os haitianos passam a ter os mesmos direitos dos brasileiros, como saúde, educação, moradia e trabalho.

Quando esses haitianos chegam ao Brasil se deparam com uma situação de vulnerabilidade social, pois se defrontam com a falta de abrigo, alimentação, documentação e a dificuldade de comunicação uma vez que a língua que se fala não é a sua. Para que esses problemas possam ser minimizados, é importante ressaltar o papel que ONG`s e a igreja

\footnotetext{
8 Ver em GOTTARDI, Ana Paula Pellegrino. De porto a porto: o eldorado brasileiro na percepção dos imigrantes haitianos em Porto Velho-RO. Dissertação de Mestrado. Pontifícia Universidade Católica do Rio Grande do Sul, 2015.
} 
juntamente com o governo federal vêm desenvolvendo junto a esse grupo direta ou indiretamente.

$\mathrm{Na}$ fuga das condições de vida miseráveis e mais especificamente ao grupo de haitianos - os desastres ambientais. Observou-se que as centenas de homens provenientes dos países de economia periférica buscam refúgio nos países de economia central, mas na maior parte das vezes não conseguem livrar-se do estigma da miséria. Trata-se de uma nova era de colonização, mas, dessa feita, uma colonização feita pelo (e em benefício do) capital.

Desse modo torna-se importante a participação da comunidade internacional para ajudar o Haiti através de recursos financeiros e apoio técnico na reconstrução do pais, para que os haitianos não necessitem sair de seu país de origem.

A revolução tecnológica acarretou consequências no mercado de trabalho, o que gerou reflexos nas massas migratórias de trabalhadores, que partiram em busca de colocação profissional. A mesma revolução tecnológica facilita o trânsito de informações e de pessoas no mundo, o que também influi nas migrações em geral.

O contato com o grupo de haitianos permitiu concluir que quando o imigrante é identificado apenas por suas características étnicas e pelo nicho do mercado de trabalho em que consegue se inserir, o que ocorre com certa constância, existe uma identificação negativa, uma identificação que faz com que lhe seja negado o reconhecimento como ser humano completo. Sua identificação como trabalhador imigrante diante da sociedade acaba servindo de empecilho para que possa conseguir melhor colocação de trabalho, ainda que se trate de trabalhador qualificado, frustrando suas esperanças de, ao atravessar fronteiras, obter acesso a um mundo melhor.

Na lei sancionada em 1980, pelo último presidente da ditadura civil-militar, João Baptista Figueiredo, eles são vistos como uma ameaça potencial à segurança da nação, dentro dessa ótica observa-se discursos semelhantes por indivíduos ligados à política.

Em leitura e análise as entrevistas, verificou-se nas narrativas que a maioria desconhece a legislação nacional e seus direitos e ao adentrar nessas novas perspectivas de vida. Geralmente afirmam que se depararam com a falta de sobre a forma de permanecer no Brasil de forma segura, direitos básicos e legislação trabalhista. Em meio a uma política descoordenada, imigrantes pauperizados se deparam com uma dura realidade burocrática para obter seus direitos mínimos dentro do país, e em outras vezes culpam diretamente a legislação nacional (Estatuto do Estrangeiro). Para tentar contornar as dificuldades vivenciadas desde o momento da partida silenciam frente às diversas mazelas nesse período migracional e de naturalização e, muitos imigrantes se submetem a situações desumanas e traumáticas. 
Ao inferir a compreensão dos fatores que levam determinados povos a migrarem se percebeu que o descuido com as questões sociais interligam entre o país de origem e o país de chegada, e que não só afeta o imigrante em si, mas toda cadeia sociológica permeando esse ciclo de desigualdade entre classes sociais.

\section{Conclusões Finais}

Ao pensarmos no termo tempo/espaço do refugiado logo nos vem em mente a ideia de provisório, temporário, onde se fixam entre o país de origem e o país de destino. Nesse contexto, os refugiados são vistos como uma questão a ser resolvida para alguns e como problema para outros.

Pensar e revisitar as questões que envolvem os deslocamentos humanos é tarefa singular e complexa. Primeiramente é necessário que haja uma proteção e reconhecimento específico dessas indagações acerca da figura humana de deslocado/migrado/refugiado uma vez que estes homens e mulheres têm buscado condições mínimas de sobrevivência. Impulsionados ou empurrados pelo aumento populacional, insustentabilidade e ocorrência dos desastres ambientais, e por diversos outros motivos já citados nesse pequeno exercício de reflexão, conclúi-se que há necessidade de novos ordenamentos, novos olhares e novos saberes associados a essa narrativa.

Sabe-se que a sociedade à medida que manifesta seus princípios morais, pressionados pelos conceitos que lhes são impostos, demonstra claramente a indiferença frente às questões humanitárias, onde controem estratégias de afastar através de políticas restritivas de migração os que ameaçam e estão ilegalmente no país (VALENCIO, 2014, p.227). Entretanto é necessário buscar ações coletivas onde o pensar e o refletir se sobrepõem ao que é imposto.

Em que pese a legislação internacional e nacional, não há uma disponibilidade por parte do governo brasileiro em exercer a função de legitimidade através das atividades de coordenação e orientação de ações voltadas para a assistência, proteção, integração e apoio aos refugiados. Assim, tem administrado o fluxo desses deslocados/imigrantes de forma provisória e em muitos casos amadora.

\section{Referências}

ACNUR; IMDH; CDHM. Políticas públicas para as migrações Internacionais. Migrantes e refugiados. 2 ed. revista e atualizada. Brasília: ACNUR; IMDH; CDHM, 2007. 
ACNUR. Ramos AC, Rodrigues G, Almeida GA (Org). 60 anos de ACNUR: perspectivas de futuro. São Paulo: Editora CL-A Cultural; 2011.

BRASIL. Constituição (1988). Constituição da República Federativa do Brasil. Brasília, DF. Senado Federal, 2011.

BRASIL. Decreto n. 6.893/2009. Regulamenta a lei n. 11.961, de 2 de julho de 2009, que dispõe sobre a residência provisória para o estrangeiro em situação irregular no território nacional, e dá outras providências. Diário Oficial da União, Brasília, DF, 3 jul. 2009.

BRASIL. Lei no 9.474 de 22 de julho de 1997. Define mecanismos para a implementação do Estatuto dos Refugiados de 1951 e determina outras providencias. Disponível em:http://www.planalto.gov.br/ccivil_03/leis/L9474.htm. Acesso em 19 abr 2017.

COMITE NACIONAL PARA OS REFUGIADOS. Sistemas de Refugio brasileiro - Desafios $e$ perspectivas. 2016. Disponível em: http://www.acnur.org/fileadmin/scripts/doc.php?file=fileadmin/Documentos/portugues/Estatis ticas/SistemadeRefugiobrasileiro-Refugio_em_numeros-05-05-2016. Acesso em 20 abr 2017.

COSTA, C. S. Refugiados Ambientais no contexto das mudanças climáticas e do direito internacional. In: Sociologia dos Desastres - Construção, Interfaces e perspectivas no Brasil. São Carlos: Rima Editora, 2009. p. 236-250.

DE MARCO, Cristhian Magnus; SILVA, Magda Cristiane Detsch da; MEZZAROBA, Orides Mezzaroba. (Org.). Diálogos sobre Direito e Justiça. $1^{\mathrm{a}}$ ed.Joaçaba/SC: Editora Unoesc, 2017.

LEONARDO, Paula Velho. Identidades em movimento: as mutações dos processos identitários e suas repercussões no exercício da cidadania. Porto Alegre: Editora Fi, 2017.

LOPES, A. M., AB'SABER, A. N., HOSSNE, W. S. O conceito de Refugiado Ambiental - é uma questão bioética? Revista Bioçthikos - Centro Universitário São Camilo. 2012; 6(4): 409-415. Disponível em: http://www.saocamilo-sp.br/pdf/bioethikos/98/05.pdf. Acesso em 19 abr 2017.

MOREIRA, J. B. Refugiados no Brasil: reflexões do do processo de integração locais. REMHU - Ver. Interdiscip. Mobil. Hum., Brasília, Ano XVII, n: 43, p. 85-98, jul/dez. 2014. Disponível em: http://www.scielo.br/pdf/remhu/v22n43/v22n43a06.pdf. Acesso jun 2017.

PINTO, A. F. R. S. Refugiados Ambientais. Revista Âmbito Jurídico. Disponível em: http://www.ambito-

juridico.com.br/site/index.php?n_link=revista_artigos_leitura\&artigo_id=6845. Acesso em 19 abr 2017.

RAMOS. E.P. Refugiados Ambientais: Em busca de Reconhecimento pelo Direito Internacional. 2011. p.18. Disponível em: http://www.acnur.org/fileadmin/scripts/doc.php?file=fileadmin/Documentos/portugues/evento s/Refugiados_Ambientais. Acesso em 21 abr 2017. 
SILVA. I. P.; WENCZENOVICZ, T.J. Invisíveis e Vulneráveis: Imigração Haitiana no Sul do Brasil. In: Anais III Seminário Internacional de Educação do Campo e III Fórum de Educação do Campo da Região Norte do Rio Grande do Sul: Resistência e Emancipação Social e Humana. Erechim, 2017. 